\title{
40 anos da Pós-graduação da EEFE-USP: \\ a sua contribuição para o avanço do conhecimento em biodinâmica do movimento humano
}

http://dx.doi.org/10.11606/1807-55092017000nesp155

\begin{tabular}{|c|c|}
\hline $\begin{array}{l}\text { Patrícia Chakur BRUM* } \\
\text { Edilamar Menezes de OLIVEIRA* } \\
\text { Júlio Cerca SERRÃO* }\end{array}$ & $\begin{array}{l}\text { *Escola de Educação } \\
\text { Física e Esporte, } \\
\text { Universidade de São } \\
\text { Paulo, São Paulo, SP, } \\
\text { Brasil. }\end{array}$ \\
\hline
\end{tabular}

\section{Introdução}

Este artigo objetiva apresentar de forma sumarizada as contribuiçóes das diferentes áreas que compóem a Biodinâmica do Movimento Humano para o desenvolvimento do programa de pós-graduação da Escola de Educação Física e Esporte da USP (PPG-EEFE-USP). Descrever uma trajetória de 40 anos não é tarefa simples, razão pela qual optamos por, partindo de uma retrospectiva histórica, analisar de modo qualitativo as açôes de ensino, pesquisa e extensão que mais impactaram na história de nosso programa de pós-graduação.

\section{Breve retrospectiva histórica da pós-graduação em educação física na USP}

Antes de se analisar as contribuiçóes da Biodinâmica para o desenvolvimento PPG-EEFEUSP faz-se necessário, em prol da contextualização dos fatos, apresentar um breve relato histórico acerca do nosso programa.

A Escola de Educação Física e Esporte da Universidade de São Paulo (EEFE-USP) foi a primeira escola de caráter civil instituída no país pelo decreto de lei estadual no 4.855 de 27 de janeiro de 1931, como integrante do antigo Departamento de Educação Física e Esportes do Estado de São Paulo. No entanto, sua aula inaugural só se deu em 4 de agosto de 1934. Integrada à Universidade de São Paulo desde dezembro de 1969, a ideia para a criação do curso de pós-graduação no nível de mestrado remonta ao início da década de 1970 quando a Escola era dirigida pelo Prof. Dr. Mário Nunes de Sousa. Torna-se importante apontar que, docentes que desenvolviam suas atividades na área que viria a ser denominada Biodinâmica do Movimento Humano tiveram papel determinante na criação do PPG-EEFEUSP. A composição da comissão nomeada em 1975 pelo então diretor da unidade, o Prof. Dr. Mário Nunes de Sousa, para estudar a criação do curso de pós-graduação é evidência do fato. Composta pelo Prof. Dr. Moacyr Brondi Daiuto, a quem coube a presidência, pelo Prof. Dr. Antonio Boaventura da Silva, pela Profa. Dra. Maria Augusta Pedutti Dal'Molin Kiss e pela Profa. Dra. Ana Maria Pellegrini. Coube a esta comissão, efetivar o levantamento das necessidades de recursos humanos e estruturação das áreas de estudo em atendimento às normas regimentais da USP, da CAPES-MEC e do Conselho Federal de Educação.

Como fruto dos esforços empreendidos, em 1976 foi nomeada a primeira comissão de pós-graduação da Escola que iniciou suas atividades em fevereiro de 1977 destinada basicamente à capacitaçáo de docentes ao Ensino Superior, assim como, promover o conhecimento científico na área de educação física com qualificação de pesquisadores. Ao examinar-se o quadro de disciplinas que compunha a estrutura curricular do curso de mestrado, observa-se marcante presença de disciplinas relacionadas a área que hoje denominamos, Biodinâmica. Isso se deu devido a dois principais fatores, o corpo 
de docentes com expertises em disciplinas afins à área de Biodinâmica e ao fato da Educação Física estar classificada em órgáos governamentais como disciplina dentro da área da saúde, onde persevera até hoje apesar da abrangência temática que compóe a área de Educação Física. Pode-se depreender desse contexto histórico que a área de Biodinâmica, portanto, contribuiu efetivamente para o desenvolvimento do curso de pós-graduaçáo na área de Educação Física na USP.

Imbuídos de espírito empreendedor, inovador e pela liderança científica na área de Educação Física no Brasil, pesquisadores da EEFE-USP também foram pioneiros em implantar o primeiro curso de doutorado em Educação Física no Brasil e na América Latina. Nesse sentido, cabe dar destaque ao Prof. Dr. Alberto Carlos Amadio, presidente da Comissáo de Pós-Graduação à época da implementação do curso de doutorado, assim como aos Professores Doutores Maria Augusta Pedutti Dal'Molin Kiss, Go Tani e Carlos Eduardo Negrão que em esforço conjunto com docentes de várias unidades da USP, estabeleceram as bases fundamentais para a criação do nosso programa de doutoramento. Mais uma vez evidencia-se a liderança de docentes da Biodinâmica em mais um momento de destaque na trajetória do
PPG-EEFE-USP. O doutorado em Educação Física inicia-se com perspectivas de consolidar a Educação Física como ciência, propiciando a formação do docente pesquisador, figura essencial no cenário universitário. Com a formaçáo de doutores em Educação Física, a área se fortaleceu e os doutores ganharam autonomia para liderar a produçáo acadêmico-científica na área de Educaçáo Física, atuando como formadores de opinião e exercendo papel multiplicador para o avanço de conhecimento na área em diferentes regiōes do país. Nesse sentido, o programa de doutorado em Educação Física da EEFE-USP desde sua criação tem liderado a formação de recursos humanos altamente qualificados além de centros de referência para o sistema universitário brasileiro. A consolidação da área de Biodinâmica na promoção do conhecimento técnico científico da educação física junto ao programa de doutorado, além de propiciar a inserçáo internacional da pesquisa em educação física, também impulsionou em 2006, a expansão das áreas de concentração do programa, sendo instituída área de concentração de pedagogia do movimento humano, pioneira no Brasil no nível de doutorado. No tópico a seguir, maiores detalhes serão fornecidos em relaçáo ao desenvolvimento do programa de pós-graduação.

\section{Biodinâmica no desenvolvimento do programa de pós-graduação da Escola de Educação Física e Esporte da USP}

Como já mencionado no tópico anterior, em fevereiro de 1977 foi criado o primeiro curso de Pósgraduação em Educação Física da América Latina, na EEFE-USP. O curso, que tinha a Educaçáo Física como área de concentração, apresentava como objetivos centrais a formação e a capacitação de docentes para o ensino superior, proporcionando a qualificação dos pós-graduandos para a pesquisa científica. A primeira defesa de mestrado em Educação Física foi realizada em dezembro de 1979 (FIGURA 1). Esta área de concentração foi extinta em maio de 1989, após a uma reformulação no programa dando início a novas áreas de concentração, conforme mencionado abaixo.

Em 1989 iniciou-se o programa de doutorado na área de concentração em Biodinâmica do Movimento Humano, dentro do Programa de Pós-graduação em Educação Física, resultado da liderança acadêmico-científica já exercida no curso mestrado e a capacidade de produção de conhecimento na área, com grande inserção nacional e também com intençóes de investir no aumento da inserção internacional do programa. O primeiro doutor em Educação Física na área de Biodinâmica do Movimento Humano ocorreu em 1994 reforçando o protagonismo da Biodinâmica, nesta que representa uma das mais importantes passagens da história do PPG-EEFE-USP. Ao longo dos anos subsequentes à criaçáo do Programa de doutorado na área de Educação Física, foi instituído o programa de doutorado direto no Programa, com a primeira defesa realizada em agosto de 1995, da área de concentração em Biodinâmica do Movimento Humano.

Também no ano de 1989, iniciou-se o Mestrado em Pedagogia do Movimento Humano, o que 
também impulsionou a pesquisa na área de Pedagogia do Movimento Humano. Já o programa de Doutorado em Pedagogia do Movimento Humano e o Mestrado em Estudos do Esporte foram iniciados somente em maio de 2006. Já no ano de 2014, o PPG-EEFE-USP passou por uma nova reestruturação com o intuito de alinhar de uma forma mais coerente, os projetos e as linhas de pesquisa às áreas de concentração do Programa. Assim, atualmente o Mestrado e Doutorado estão estruturados em duas áreas de concentração, a saber: Estudos Biodinâmicos da Educação Física e Esporte e Estudos Socioculturais e Comportamentais da Educação Física e Esporte. Estas áreas de concentração foram aprovadas em reunião da Comissão de Pós-Graduação em fevereiro de 2014 e ativadas em janeiro de 2015, nesta última data também foram desativadas as três áreas anteriores.

Na FIGURA 1, apresentamos dados das defesas de mestrado, doutorado e doutorado direto até maio de 2017. Portanto, até o momento, o PPGEEFE-USP como um todo já finalizou 17 defesas de doutorado direto, formou 548 mestres e 176 doutores.

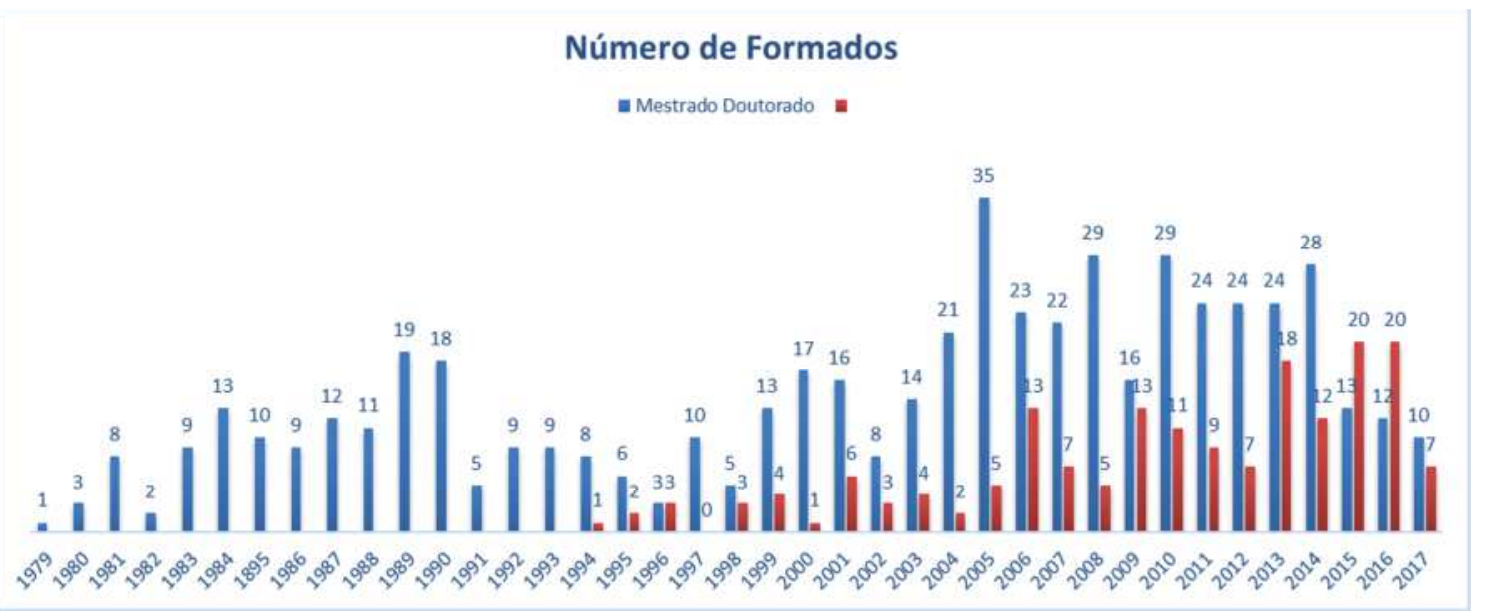

FIGURA 1 - Número de Dissertações de Mestrado e Teses de Doutorado defendidas nos Cursos de Pós-graduação da EEFE-USP de 1979 a maio de 2017.

\section{Biodinâmica do Movimento do Corpo Humano na atualidade}

Após a contextualização do papel da Biodinâmica nas diferentes etapas de desenvolvimento do programa de pós-graduação da Escola de Educação Física e Esporte da USP (PPG-EEFE-USP), cabenos apresentar as contribuições da Biodinâmica na atualidade. Para tanto, apresentaremos uma análise sumária e qualitativa das açôes desenvolvidas pela Biodinâmica na história recente do PPG-EEFE-USP.

Conforme apontado anteriormente, o PPGEEFE-USP sempre ocupou posição de destaque no cenário da pós-graduação nacional. Fomos os primeiros e até hoje somos o único programa da Área 21 da CAPES a alcançar o conceito 7, condição que nos caracteriza como um programa de inserção internacional. Muitas foram as contribuiçōes da
Biodinâmica para a consecução desta importante posição acadêmica. Apresentar um breve sumário dessas contribuições é a intenção deste tópico.

A principal meta do PPG-EEFE-USP é formar recursos humanos para atuação na pesquisa e no ensino superior, que se destaquem pelo profundo domínio de sua área temática, e pela sua capacidade de liderança. A metodologia empregada para consecução desses objetivos envolve um conjunto de processos que integram os alunos, os laboratórios, os grupos de pesquisa e os orientadores do programa. Dentre as açóes que compreendem todo o processo de formação acadêmico científica, merecem destaque as atividades científicas relacionadas ao desenvolvimento das dissertaçóes e teses, e 
a participação em disciplinas curriculares. Os orientadores da área de concentração em Estudos Biodinâmicos da Educaçáo Física e do Esporte contribuem de forma intensa em ambas as açôes.

Uma das atuaçóes mais visíveis da área de concentração em Estudos Biodinâmicos da Educação Física e do Esporte ocorre no oferecimento de disciplinas. Orientadores do programa oferecem um amplo conjunto de disciplinas, voltadas ao desenvolvimento acadêmico científico dos alunos. Tais disciplinas são oferecidas em diversas dimensōes. Nossos orientadores participam de disciplinas obrigatórias cujo conteúdo aborda questóes de caráter científico geral como a metodologia da pesquisa científica, a filosofia da ciência e a estatística. São ainda responsáveis por um conjunto bastante extenso de disciplinas que abordam temas mais específicos e afeitos às linhas de pesquisa desenvolvidas no programa. Apesar de náo estarem diretamente associados às disciplinas relacionados à docência no ensino superior, nossos orientadores têm destacada ação na supervisão dos alunos que desenvolvem atividades no Programa de Aperfeiçoamento de Ensino (PAE) da USP. O PAE é um programa destinado aos pós-graduandos da USP que tem por meta central aprimorar a sua formação didática no âmbito da graduação. Enquanto supervisores dos pós-graduandos, os orientadores da Biodinâmica têm atuação marcante no programa, condição que aponta o compromisso da nossa área com a preparação pedagógica de nossos alunos. Mais recentemente, os orientadores também participado do programa de capacitação didática para pós-doutorandos da Universidade de Sáo Paulo supervisionando os mesmos junto as disciplinas da graduação em atendimento à resoluçáo no 7151 de dezembro de 2015.

Ainda no que se refere ao oferecimento de disciplinas, outro importante aspecto merece ser destacado. Nos últimos anos, os orientadores da Biodinâmica têm se empenhado para oferecer disciplinas que, a partir da participação de mais de um orientador, possam oferecer ao aluno uma perspectiva mais abrangente dos temas abordados. Como exemplo tome-se a disciplina Seminários em Biodinâmica, cujo propósito central é oportunizar ao aluno vivências que extrapolem o seu tema específico de estudo. Por além de estimular uma formação mais ampla, tal estratégia representa um forte estímulo ao desenvolvimento de novas parcerias de investigação. A avaliação dessas disciplinas coordenadas pela Comissão de Pós-Graduação, apontam que tais metas vêm sendo alcançadas com pleno êxito.
No que se refere às atividades de pesquisa, as oportunidades oferecidas pela Biodinâmica são bastante diversificadas e abrangentes. Evidência do fato pode ser obtida por intermédio da análise das linhas de pesquisa desenvolvidas pelos orientadores dessa área. Essas linhas, que traduzem os campos de investigação desenvolvidos pelos orientadores da Biodinâmica, apontam a riqueza de possibilidades oferecidas aos pós-graduandos. Dentre os tópicos abordados figuram alguns como: a biomecânica externa e interna na locomoção humana e no esporte; os efeitos agudo e crônico do exercício no sistema cardiovascular; os mecanismos e integração da nutrição, atividade física e genética no desempenho físico esportivo; os fatores que influenciam o rendimento esportivo; a aquisição de habilidades motoras ao longo do ciclo de vida; e a aquisição de padróes fundamentais de movimento e suas combinaçóes.

O êxito alcançado no desenvolvimento das atividades de pesquisa pode ser dimensionado a partir de diferentes indicadores dentre os quais destacamos a evolução da produção na área, a captaçáo de recursos, e o recebimento de prêmios acadêmicos.

Nos últimos anos, observou-se um expressivo aumento na produção acadêmica na área da Biodinâmica. Mais do que o aumento no número de produçóes, apontamos uma nítida e consistente tendência de qualificaçáo dessas produçóes. Tendo como referência de qualidade o sistema Qualis da CAPES, observa-se um incremento no número de artigos publicados em periódicos dos estratos A1 e A2, associados a uma reduçáo na publicação nos estratos inferiores. Outro aspecto que merece destaque diz respeito à produção com a colaboraçáo de pesquisadores estrangeiros. Em nossa história recente, observa-se um sensível incremento no número dessas publicaçôes, que congregam esforços de pesquisadores do nosso programa junto à pesquisadores de diversos outros países, dentre os quais a Austrália, Bélgica, Canadá, Estados Unidos, França, Itália, Moçambique, Noruega, Nova Zelândia, Portugal, e Reino Unido. Observa-se, portanto, um claro compromisso dos orientadores e alunos da Biodinâmica com a qualidade e com a internacionalizaçáo de suas ações de investigação, condição que evidencia o amadurecimento de nossas linhas e projetos científicos.

As contribuiçôes científicas da Biodinâmica não se restringem à pós-graduação. Em 2017, o curso de graduaçâo da EEFE foi classificado pela consultoria britânica Quacquarelli Symonds na posiçáo $31^{\mathrm{a}}$ no "ranking" dos melhores cursos de graduação na 
área de esporte do mundo. A avaliação levou em consideração o impacto da produção científica, bem com a reputação da instituição no mercado de trabalho e no ambiente acadêmico. Dados como esse evidenciam que a contribuiçáo científica da Biodinâmica tem impactado não apenas na qualidade do PPG-EEFE-USP como também nas atividades em nível de graduação, colaborando dessa forma com a integração das ações de graduaçáo e pós-graduação, estabelecida como meta da instituição.

Ainda como evidência da excelência das atividades de pesquisa desenvolvidas na Biodinâmica, apontamos a expressiva participação dos docentes em projetos de grande porte, financiados pelas mais importantes agências de fomento à pesquisa, além da participação em importantes núcleos como os Centros de Pesquisa, Inovação e Difusão (CEPIDs) e Institutos Nacionais de Ciência e Tecnologia (INCTs).

O reconhecimento da qualidade das atividades de pesquisa desenvolvidas pela Biodinâmica também pode ser dimensionado pelos prêmios recebidos por nossos alunos. Nos últimos anos, fomos agraciados em duas ocasióes (2011 e 2012) com o Prêmio CAPES de Teses, além de termos recebido em 2013, menção honrosa no Prêmio Tese Destaque da PróReitoria de Pós-Graduação da USP.

Conforme apontado anteriormente, a meta primordial do PPG-EEFE-USP é formar recursos humanos com profundo domínio acadêmicocientífico de sua área, e que se destaquem por sua capacidade de liderança. A análise do perfil dos

\section{Conclusão}

As consideraçóes tecidas nesse capítulo, ainda que sumárias, permitem concluir que a trajetória do PPG-EEFE-USP se confunde com própria trajetória da Biodinâmica. Não há como negar que o desenvolvimento acadêmico-científico desta área, criou condiçốes para que os anseios da instituição, voltados à criação de um programa de pós-graduação, pudessem ser concretizados. Neste sentido, deve-se destacar o papel crucial desenvolvido por docentes da Biodinâmica na proposição daquele que viria a ser o primeiro programa brasileiro de pós-graduaçáo na Educação Física. Ainda que seja difícil dimensionar com a necessária precisão, é igualmente inegável a participação de docentes vinculados à Biodinâmica na consecução de importantes conquistas que egressos do que desenvolveram suas atividades em nossa área de concentraçáo aponta a grande contribuição da Biodinâmica para a consecução dessa importante meta.

Egressos que desenvolveram seus programas em nossa área de concentração ocuparam papéis de destaque no cenário acadêmico. Dentre muitas outras participaçóes, nossos egressos ocuparam a Vice-Reitoria de Pesquisa e Pós-Graduação (Universidade de Passo Fundo), a diretoria de instituições de ensino superior (USP, UFMG e UEL), a coordenação de programa de pós-graduação (USP, UFMG e UEL), e a coordenação de curso de graduação (USP, UNINOVE, UNICSUL e UNIP). Egressos de nossa área de concentração ainda ocuparam posiçóes estratégicas na administração da pós-graduação a partir do exercício de importantes cargos e funçóes na CAPES, e nas agências de fomento à pesquisa, dentre as quais a FAPESP. Deve-se ainda destacar a sistemática participaçáo de nossos egressos em grande parte dos programas de pós-graduação das mais importantes instituiçóes de ensino brasileiras. Caracteriza-se, desta forma, que as contribuiçóes da Biodinâmica extrapolam os limites do PPG-EEFE-USP, e se estendem para grande parte das IES brasileiras.

Apesar de breve e sumarizada, essa breve análise das açôes da Biodinâmica no âmbito da pósgraduação buscou apontar a contribuiçáo de nossa área na consolidação do PPG-EEFE-USP neste importante momento de sua história. marcaram a história do PPG-EEFE-USP, dentre as quais se destacam a criação do primeiro programa de doutoramento na área, e a obtenção da maior nota oferecida pela CAPES aos programas de pós-graduação brasileiros. Não há dúvidas que a consolidação da Biodinâmica, cujos frutos mais tangíveis foram o aumento da produção intelectual e a internacionalização das nossas açóes de ensino e pesquisa, formaram um dos alicerces centrais que permitiram a EEFE-USP atingir a nota máxima na avaliação da CAPES. É igualmente inegável que o desenvolvimento do PPG-EEFEUSP foi mola propulsora para a consolidação da Biodinâmica como área de conhecimento da Educação Física. Desta breve análise, onde os relatos de interferências 
mútuas são abundantes, pode-se concluir que a história da Biodinâmica se confunde com a história do PPG-EEFE-USP. Uma relação antiga, sólida e altamente profícua não apenas para a EEFE-USP, como para toda a área da Educação Física e do Esporte.

\section{Nota}

Sugestōes de consulta: AmADIO ${ }^{1-3}$ e CANO ${ }^{4}$.

\section{Referências}

1. Amadio AC. A pós-graduação da Escola de Educação Física da Universidade de São Paulo: análise da situação e perspectivas de desenvolvimento. Rev Paul Educ Fís. 1990;4:11-33.

2. Amadio AC. Trajetória da pós-graduação stricto sensu na Escola de Educação Física e Esporte da Universidade de São Paulo após 25 anos de produção acadêmica. Rev Bras Ciênci Esporte. 2003;24;27-47.

3. Amadio AC. Consolidação da pós-graduação "stricto sensu" da Escola de Educação Física e Esporte da Universidade de São Paulo: trajetória acadêmica após 30 anos de produção. Rev Bras Educ Fís Esporte. 2007;21(NEsp):25-36.

4. Cano T. Análise do programa de pós-graduação em educação física da USP, em nível de mestrado como sugestão para implantação na Colômbia [dissertação]. São Paulo: Universidade de São Paulo, Escola deEducação Física; 1985.

ENDEREÇO

Patrícia Chakur Brum Escola de Educação Física e Esporte - USP Av. Prof. Mello Moraes, 65 05508-030 - São Paulo - SP - BRASIL e-mail: pcbrum@usp.br 